\title{
The emerging role of GATA transcription factors in development and disease
}

\author{
MARJOLEIN HFM LENTJES ${ }^{1}$, HANNEKE EC NIESSEN ${ }^{1}$, YOSHIMITSU AKIYAMA ${ }^{2}$, \\ ADRIAAN P DE BRUÏNE ${ }^{1}$, VEERLE MELOTTE ${ }^{1}$, MANON VAN ENGELAND ${ }^{1 *}$ \\ ${ }^{1}$ Department of Pathology, GROW - School for Oncology and Developmental Biology, Maastricht University \\ Medical Center, Maastricht, The Netherlands, and ${ }^{2}$ Department of Molecular Oncology, Graduate School of \\ Medicine and Dentistry, Tokyo Medical and Dental University, Tokyo, Japan
}

The GATA family of transcription factors consists of six proteins (GATA1-6) which are involved in a variety of physiological and pathological processes. GATA1/2/3 are required for differentiation of mesoderm and ectoderm-derived tissues, including the haematopoietic and central nervous system. GATA4/5/6 are implicated in development and differentiation of endoderm- and mesoderm-derived tissues such as induction of differentiation of embryonic stem cells, cardiovascular embryogenesis and guidance of epithelial cell differentiation in the adult.

The importance of GATA factors for development is illustrated by the embryonic lethality of most single GATA knockout mice. Moreover, GATA gene mutations have been described in relation to several human diseases, such as hypoparathyroidism, sensorineural deafness and renal insufficiency (HDR) syndrome, congenital heart diseases (CHDs) and cancer. GATA family members are emerging as potential biomarkers, for instance for the risk prediction of developing acute megalokaryblastic leakemia in Down syndrome and for the detection of colorectal- and breast cancer.

\section{The origin and molecular structure of the GATA family}

In vertebrates, six GATA transcription factors have been identified. Based on phylogenetic analysis and tissue expression profiles, the GATA family can be divided into two subfamilies, GATA1/2/3 and GATA4/5/6 (Ref. 1). Although in non-vertebrates GATA genes are linked together onto chromosomes, in humans they are segregated onto six distinct chromosomal regions (Table 1), indicating segregation during evolution (Ref. 2). Most GATA genes encode for several transcripts and protein isoforms. GATA proteins have two zinc finger DNA binding domains, Cys- $\mathrm{X}_{2}-\mathrm{C}-\mathrm{X}_{17}-\mathrm{Cys}-\mathrm{X}_{2}$-Cys (ZNI and ZNII), which recognise the sequences (A/T)GATA(A/G) (Fig. 1) (Ref. 3). Amongst the six GATA binding proteins, the zinc finger domains are more than $70 \%$ conserved, while the sequences of the amino-terminal and carboxyl-terminal domains exhibit lower similarity (Ref. 4). In non-vertebrates GATA transcription factors have been identified that contain mostly one zinc finger, i.e. in Drosophila melanogaster and
Caenorhabditis elegans (Ref. 3). The C-terminal zinc finger (ZNII) exists in both vertebrates and non-vertebrates indicating that ZNI was duplicated from ZNII (Ref. 2).

\section{Tissue-specific roles of GATA factors in development and disease}

\section{Haematopoietic system}

GATA1/2/3 knockout mice die at the embryonic stage due to haematological abnormalities (Table 2), indicating a pivotal role of these transcription factors in haematopoietic development (Ref. 1).

GATA1, the first recognised member of the GATA family, is specifically expressed during haematopoietic development of erythroid, and megakaryocytic cell lineages (Fig. 2) (Ref. 11). Loss of GATA1 in mouse embryo-derived stem cells results in a complete lack of primitive erythroid precursor production (Ref. 5). Definitive erythroid precursors, on the other hand, are normally produced, but undergo a maturation arrest at the proerythroblast stage followed by apoptosis (Ref. 12). Ablation of GATA1 in adult mice also results in a maturation arrest at the same proerythroblast stage (Ref. 13). The requirement of the different GATA1 functional domains during primitive and definitive erythropoiesis has been investigated in vivo, showing that both zinc fingers are needed to rescue GATA1 germline mutant mice (Ref. 14). In haematopoietic stem cells (HSCs), GATAl gene expression is suppressed, which is indispensable for the maintenance of these stem cells. The mechanism behind this suppression is not fully understood yet. Recently, it was shown that decreased DNA

(C) Cambridge University Press 2016. This is an Open Access article, distributed under the terms of the Creative Commons Attribution licence (http:// creativecommons.org/licenses/by/4.0/), which permits unrestricted re-use, distribution, and reproduction in any medium, provided the original work is properly cited. 


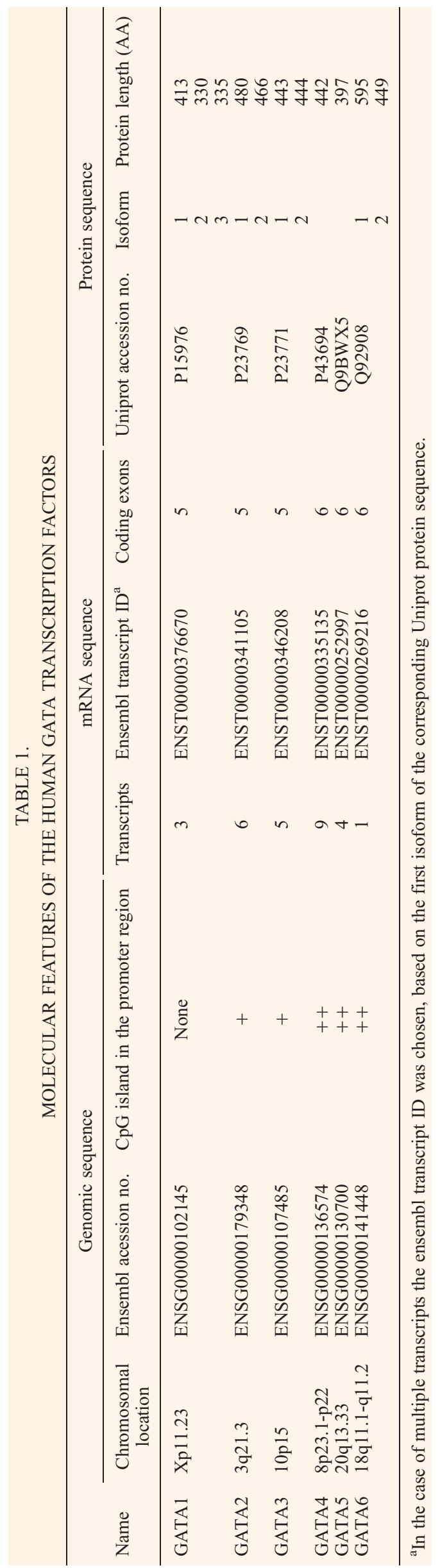

methylation of the GATA1 locus leads to increased GATA2 binding and that increased GATA2 binding results in GATAl gene transactivation. According to these study results, Takai et al. proposed a mechanism in which GATA1 hypomethylation results in an accessible locus for GATA2 binding which enables transactivation of GATAl gene expression to initiate erythropoiesis in megakaryo-erythroid progenitors (Ref. 15). Loss of GATA1 results in a marked increase of GATA2 expression, indicating not only that GATA2 partially compensates for GATA1 but also that GATA1 suppresses GATA2 transcription during normal erythropoiesis (Ref. 16). This suppression is mediated by the displacement of GATA2 from its upstream enhancer by increasing levels of GATA1 referred to as the 'GATA switch' (Ref. 17). The combined loss of GATA1 and GATA2 in double-knockout embryos leads to an almost complete absence of primitive erythroid cells, suggesting functional overlap between these transcription factors early in the primitive erythropoiesis (Ref. 18).

Requirement of functional GATA1 for haematopoiesis is also observed in several human diseases, such as anaemia, leukaemia and thrombocytopenia (Table 3). Splice site mutations of GATA1 have been found in a family with macrocytic anaemia and in patients with Diamond-Blackfan anaemia (an anaemia characterised by a selective hypoplasia of erythroid cells), resulting in impaired production of the full-length form of the GATA1 protein (Refs 19, 20).

Conditional megakaryocytic lineage specific GATA1 knockout mice show excessive marrow megakaryocyte proliferation whereas the platelet numbers are decreased. The maturation of these hyperproliferated megakaryocytes is severely impaired and the produced platelets are structurally and functionally abnormal (Ref. 21). Additionally, megakaryocyte-expressed genes with functional GATA1-binding sites (e.g. STAT1) are downregulated in GATA1 $^{-/-}$megakaryocytes (Ref. 22). Loss of GATA1 leads to overexpression of GATA2 in megakaryocytes. However GATA1-deficient megakaryocytes still show abnormal megakaryocytic proliferation and differentiation, establishing no functional redundancy of these transcription factors in megakaryopoiesis (Ref. 23). In contrast to erythropoiesis, GATA2 remains to be expressed after the GATA switch in late megakaryopoiesis, suggesting a divergent function for both GATA proteins (Ref. 24).

Children with trisomy 21 are at risk of developing leukaemia, in particular acute megakaryoblastic leukaemia (AMKL). Nearly all Down syndrome patients with AMKL harbour somatic mutations in the GATA1 gene (Table 3) (Ref. 25), predominantly leading to an N-terminal truncated 'short' GATAl protein (GATA1s) (Ref. 26). Inadequate GATA1 mediated repression of specific oncogenic factors contributes to megakaryocytic abnormalities (Ref. 27). Analysis of Down syndrome children with transient 


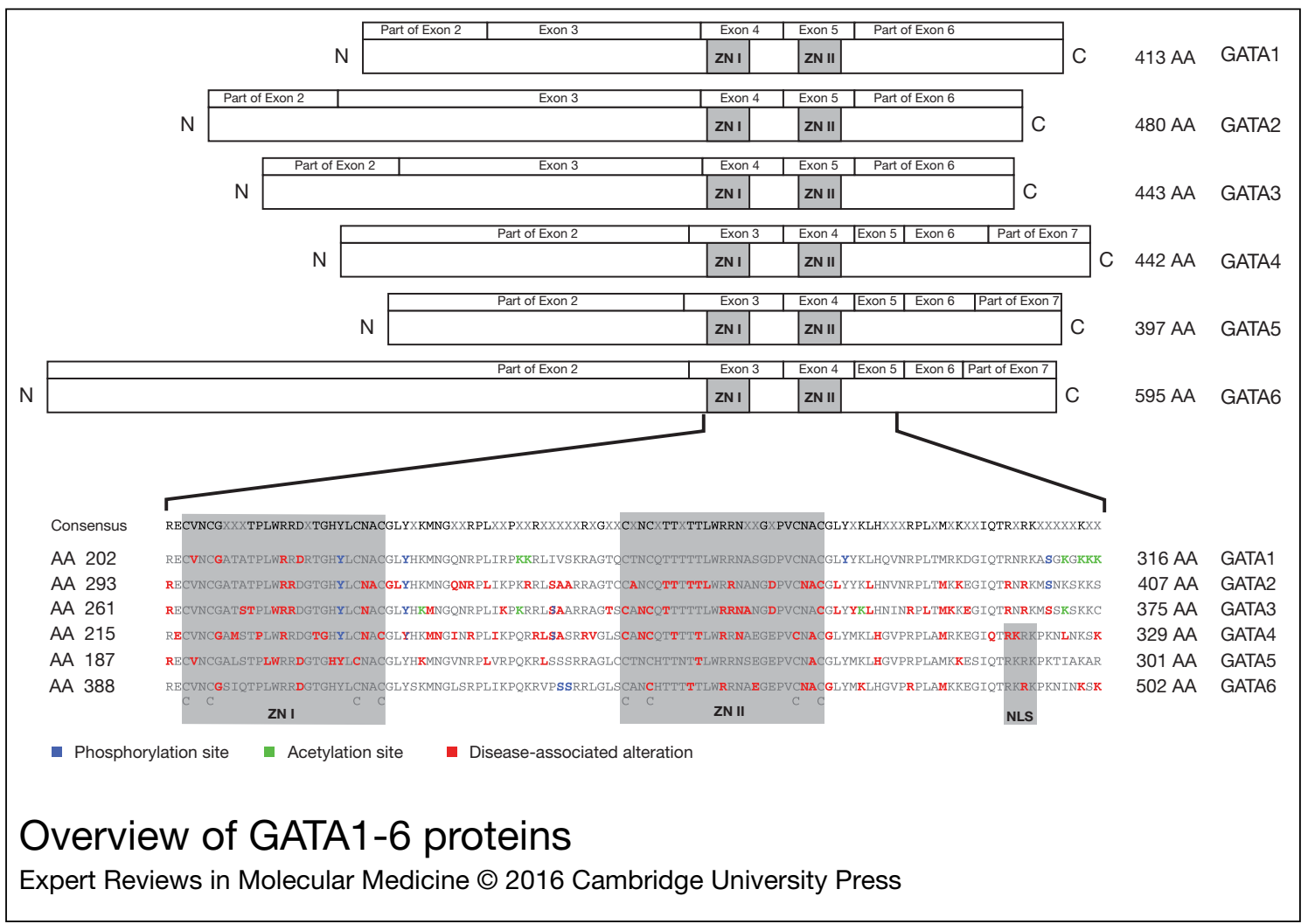

FIGURE 1 .

Overview of GATA1-6 proteins. The GATA proteins are depicted in the upper part of the figure. The GATA proteins are aligned according to the location of the zinc fingers (ZNI and ZNII). The exon boundaries are depicted above the protein structure. For GATA4 the TADI and TADII are shown. In the lower part of the figure the regions around the zinc fingers are enlarged, with the correspondingAA numbers written next to the GATA sequence. Posttranslational modification (post-transciptional modification) sites and disease-associated alterations are marked on top of the corresponding AA. AA, amino acid; TAD, transcriptional activation domains.

myeloproliferative disorder (TMD), which is considered a potential precursor to AMKL, also revealed GATA1 mutations (Ref. 28). Noticeable the GATA1 mutation in TMD and subsequent AMKL is identical, suggesting that GATA1 mutations are early events in the development of AMKL in trisomy 21-children (Ref. 29). Not all TMD Down syndrome neonates with a GATA1 mutation progress to AMKL, indicating the need for more molecular events contributing to the pathogenesis of AMKL. Recently, Yoshida et al. reported newly acquired driver mutations, which lead to the development from TMD to Down syndromeAMKL (Refs 30, 31).
The mechanism behind the leukaemogenesis remains elusive. Based on mutational spectrum analysis of the GATA1 locus in Down syndrome AMKL, Cabelof et al. hypothesised that increased oxidative stress because of trisomy 21, uracil accumulation and reduced DNA repair together driving leukaemogenesis in Down syndrome (Ref. 32). Recently it was shown that GATA1 mutations protect megakaryocytes from activated AKT-induced apoptosis (Ref. 33). Additionally, trisomy 21 itself increases HSC frequency, clonogenicity and megakaryocyte-erythroid output with associated megakaryocyte-erythroid progenitor expansion (Refs 34, 35, 36). Another

TABLE 2.

PHENOTYPE OF GATA KNOCKOUT MICE

\begin{tabular}{|c|c|c|c|}
\hline Name & $\begin{array}{l}\text { Phenotype } \\
\text { (embryonic day) }\end{array}$ & Abnormality & Reference \\
\hline GATA1 & $\operatorname{die}(11.5-12.5 \mathrm{dpc})$ & Defective erythroid cell maturation & (Ref. 5) \\
\hline GATA2 & $\operatorname{die}(12.5 \mathrm{dpc})$ & Severe anaemia & (Ref. 6) \\
\hline GATA3 & die $(11-12 \mathrm{dpc})$ & Massive internal bleeding and severe deformities of the brain and spinal cord & (Ref. 7) \\
\hline GATA4 & die $(9.5 \mathrm{dpc})$ & Defects of heart morphogenesis and ventral closure of the forgut & (Ref. 8) \\
\hline GATA5 & Viable and fertile & $\begin{array}{l}\text { Females exhibited pronounced genitourinary abnormalities that included vaginal and } \\
\text { uterine defects and hypospadias }\end{array}$ & (Ref. 9) \\
\hline GATA6 & $\operatorname{die}(5.5-7.5 \mathrm{dpc})$ & defects of visceral endoderm function and subsequent extra-embryonic endoderm & (Ref. 10) \\
\hline
\end{tabular}

$D p c$, days post coïtum. 


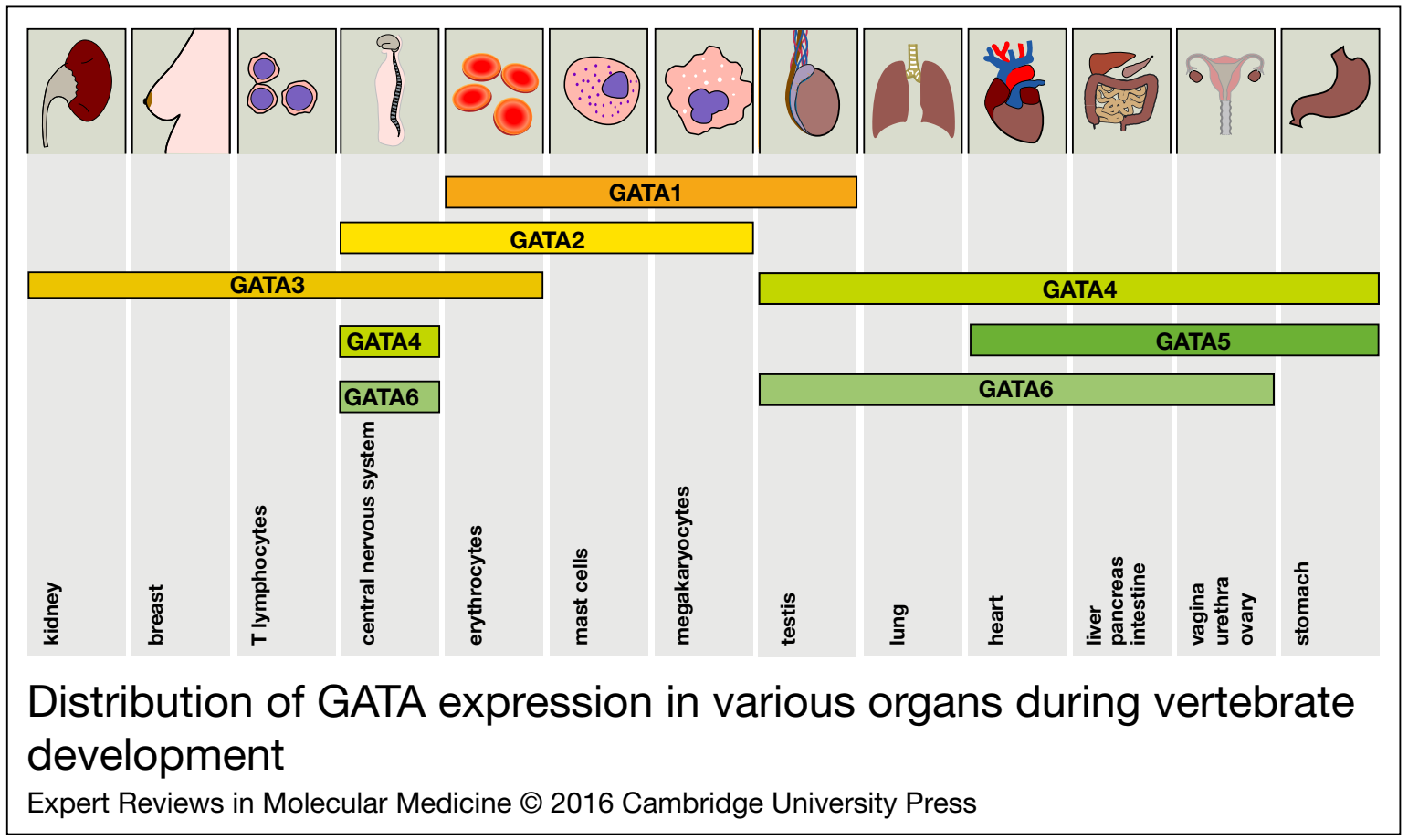

FIGURE 2

Distribution of GATA expression in various organs during vertebrate development. The expression of all GATA factors is depicted in the corresponding tissues. The distribution of the expression patterns roughly reflects the two GATA subgroups (GATA1/2/3 versus GATA4/5/6).

hypothesis is that upregulation of runt-related transcription factor 1 (RUNX1), which physically interacts with GATA1, due to trisomy 21 leads to the induction of GATA1 transcription during embryogenesis, thereby leading to transcription-associated mutagenesis (Ref. 37). Recently it is shown that loss of type I interferon (IFN) signalling contributes to GATA1s-induced megakaryocyte hyperproliferation, suggesting AMKLtreatment with IFN- $\alpha$ administration (Ref. 38).

GATA1 mutations are also detected in a specific form of X-linked hereditary thrombocytopenia and are described with and without thalassemia (Table 3 and Supplemental Table 1). Hereditary thrombocytopenia without thalassemia has been associated with GATA1 missense mutations that are located in the N-terminal zinc finger region. These mutations lead to loss or inhibition of GATA1 interaction with friend-ofGATA(FOG)1-cofactor (Ref. 39). The degree of disrupted GATA1-FOG1 interaction depends on the mutation, explaining different clinical presentations (Ref. 40). The only GATA1 mutation reported in hereditary X-linked thrombocytopenia with thalassemia is the missense mutation R216Q which is located in the DNA binding surface of the GATA1 N-terminal zinc finger and results in reduced DNA binding rather than affecting GATA1-FOG1 interaction (Ref. 41).

In vertebrates, GATA2 is expressed in haematopoietic progenitor cells (HPCs), early erythroid cells, mast cells and megakaryocytes, closely resembling the cellular distribution of GATA1 (Fig. 2). A deficit in primitive erythropoiesis is apparent in $G A T A 2^{-/-}$ mice since the total number of blood cells during embryonic development is markedly reduced, leading to lethality because of severe anaemia (Table 2) (Ref. 6). In $G A T A 2^{+/-}$mice haematopoietic defects are seen within HSCs and granulocyte-macrophage progenitor cells. Moreover, the loss of GATA2 in adult mice leads to profound abnormalities in definitive haematopoiesis, also directing to a defect at the level of HSCs (Refs 6, 42, 43). The function of GATA2 in haematopoietic development has recently been reviewed by Bresnick et al. (Ref. 44), describing GATA2 as one of the key components establishing the transcriptional program for early haematopoietic development.

Two different GATA2 alterations have been reported in patients with chronic myeloid leukemia (CML) during blast crisis formation (Table 3). In contrast to the in-frame deletion $\Delta 341-346$, which leads to decreased transcriptional activation, GATA2 L359V is a gain-of-function mutation and leads to increased DNA binding. Transduction of GATA2 L359V (in vitro and in vivo) resulted in disturbed myelomonocytic differentiation/proliferation, suggesting GATA2 mutations are involved in the acute myeloid transformation of CML (Ref. 45).

GATA2 gene mutations that predisposed to myelodysplastic syndrome (MDS) and acute myeloid leukaemia (AML) were reported (Supplemental Table 1). This occurred either in the absence (non-syndromic) or presence of certain syndromes, including Emberger syndrome and monoMAC syndrome 
TABLE 3.

GATA TRANSCRIPTION FACTORS IN DISEASE

\begin{tabular}{|c|c|c|c|c|}
\hline & Disease & Abberation & Location & Consequence \\
\hline \multirow[t]{6}{*}{ GATA1 } & XLT & MS mut & $\mathrm{ZnF} 1$ & FOG1 interaction $\downarrow$ \\
\hline & XLTT & MS mut & $\mathrm{ZnF} 1$ & DNA binding $\downarrow$ \\
\hline & $\begin{array}{l}\text { Anaemia (e.g. Diamond- } \\
\text { Blackfan anaemia) }\end{array}$ & $\begin{array}{l}\text { Splice site mutation, mutation } \\
\text { initiation codon }\end{array}$ & exon 2 & $\begin{array}{l}\text { Only short for or loss of the full length } \\
\text { GATA1 isoform }\end{array}$ \\
\hline & $\begin{array}{l}\text { Congenital erythropoietic } \\
\text { porphyria }\end{array}$ & MS mut & $\mathrm{ZnF} 1$ & Unknown \\
\hline & TMD and AMKL in DS & $\begin{array}{l}\text { FS INS and DEL, NS mut and } \\
\text { splice site mutation }\end{array}$ & $\begin{array}{l}\text { Intron } 1 \text {, exon } 2 \text { and } \\
3\end{array}$ & $\begin{array}{l}\text { Protein truncation, transcriptional } \\
\text { activation } \downarrow\end{array}$ \\
\hline & AMKL without DS & INS & exon 2 & Protein truncation \\
\hline \multirow[t]{4}{*}{ GATA2 } & $\begin{array}{l}\text { Chronic myeloid } \\
\text { leukaemia }\end{array}$ & MS mut, FS DEL & $\mathrm{ZnF} 2$ & DNA binding $\uparrow$, transcriptional activation $\downarrow$ \\
\hline & $\begin{array}{l}\text { DCML / MonoMAC / } \\
\text { Emberger syndrome }\end{array}$ & $\begin{array}{l}\text { FS INS and DEL, MS and NS mut, } \\
\text { full gene DEL }\end{array}$ & $\begin{array}{l}\mathrm{ZnF} 2,5^{\prime} \mathrm{UTR} \\
\quad \text { intron } 5\end{array}$ & $\begin{array}{l}\text { Nonfunctional protein, nonsense- } \\
\text { mediated decay }\end{array}$ \\
\hline & $\begin{array}{l}\text { Myelodysplastic } \\
\text { syndrome }\end{array}$ & $\begin{array}{l}\text { FS INS and DEL, MS and NS mut, } \\
\text { full gene DEL }\end{array}$ & exon, intron, $5^{\prime} \mathrm{UTR}$ & Protein truncation, DNA binding $\downarrow$ \\
\hline & Acute myeloid leukaemia & MS mut, FS INS, full gene DEL & $\mathrm{ZnF} 1, \mathrm{ZnF} 2$, exons & Nonfunctional protein \\
\hline \multirow[t]{5}{*}{ GATA3 } & HDR syndrome & $\begin{array}{l}\text { MS and NS mut, FS INS and DEL, } \\
\text { splice site mutation,partial and } \\
\text { full gene DEL }\end{array}$ & $\mathrm{ZnF} 1, \mathrm{ZnF} 2$, exons & $\begin{array}{l}\text { Protein truncation, FOG2 interaction } \downarrow \text {, } \\
\text { DNA binding/affinity } \downarrow\end{array}$ \\
\hline & Breast cancer & MS and NS mut, FS INS and DEL & ZnF2, exons & Protein truncation, nonfunctional protein \\
\hline & T-ALL & MS mut, FS DEL, in-frame DEL & $\mathrm{ZnF} 1, \mathrm{ZnF} 2$ & Likely loss of function \\
\hline & B-ALL & SNP & Intron 3 & Unknown \\
\hline & UCC and RCC & CpG methylation & Promoter & Transcriptional activation $\downarrow$ \\
\hline \multirow[t]{6}{*}{ GATA4 } & CHD & $\begin{array}{l}\text { MS and NS mut, FS INS and DEL, } \\
\text { SNP, full gene DEL, gene } \\
\text { duplication }\end{array}$ & $\begin{array}{l}\mathrm{ZnF} 1, \mathrm{ZnF} 2 \text {, exons, } \\
\text { 3'-UTR, introns, } \\
\text { promoter }\end{array}$ & $\begin{array}{l}\text { Protein truncation, DNA binding/affinity } \downarrow \text {, } \\
\text { transcriptional activation } \downarrow \text {, TBX5 } \\
\text { interaction } \downarrow \text {, changed RNA folding }\end{array}$ \\
\hline & Pancreatic agenesis & $\begin{array}{l}\text { MS mut, intragenic and full gene } \\
\text { deletion }\end{array}$ & $\mathrm{ZnF} 2$ & $\begin{array}{l}\text { Transcriptional activation } \downarrow \text {, DNA } \\
\text { binding } \downarrow\end{array}$ \\
\hline & GI cancer & CpG methylation, amplification & Promoter, $8 \mathrm{p}$ & Transcriptional activation $\downarrow / \uparrow$ \\
\hline & Glioblastoma multiforme & $\begin{array}{l}\text { CpG methylation, FS INS and } \\
\text { DEL }\end{array}$ & $\begin{array}{l}\text { Promoter, } \mathrm{ZnF} \\
\quad \text { domains, C } \\
\text { terminal region }\end{array}$ & Transcriptional activation $\downarrow$ \\
\hline & Ovarian cancer & $\begin{array}{l}\text { Hypoacetylation, loss } \\
\text { trimethylation, } \mathrm{CpG} \\
\text { methylation }\end{array}$ & $\begin{array}{l}\text { Histone } 3 \text { and } 4 \text {, } \\
\text { lysine } 4\end{array}$ & Transcriptional activation $\downarrow$ \\
\hline & $\begin{array}{l}\text { Other cancers (e.g. lung, } \\
\text { DLBCL) }\end{array}$ & $\mathrm{CpG}$ methylation & Promoter & Transcriptional activation $\downarrow$ \\
\hline \multirow[t]{2}{*}{ GATA5 } & $\mathrm{CHD}$ & MS and NS mut & $\mathrm{ZnF} 1, \mathrm{ZnF} 2$ & Transcriptional activation $\downarrow$ \\
\hline & $\begin{array}{l}\text { Cancer (e.g. GI cancer, } \\
\text { RCC) }\end{array}$ & CpG methylation & Promoter & Transcriptional activation $\downarrow$ \\
\hline \multirow[t]{6}{*}{ GATA6 } & $\mathrm{CHD}$ & $\begin{array}{l}\text { MS and NS mut, duplication and } \\
\text { DEL }\end{array}$ & $\mathrm{ZnF} 1, \mathrm{ZnF} 2$, exons & Transcriptional activation $\downarrow$ \\
\hline & Pancreatic agenesis & MS and NS mut, FS INS and DEL & Znf2, exons & Transcriptional activation $\downarrow$ \\
\hline & Ovarian cancer & $\begin{array}{l}\text { Hypoacetylation, loss } \\
\text { trimethylation, upregulation }\end{array}$ & $\begin{array}{l}\text { Histone } 3 \text { and } 4, \\
\text { lysine } 4\end{array}$ & Transcriptional activation $\downarrow / \uparrow$ \\
\hline & GI cancer & Amplification, CpG methylation & $18 \mathrm{q}$, promoter & Transcriptional activation $\downarrow / \uparrow$ \\
\hline & Pancreatobiliary cancer & Amplification & $18 \mathrm{q} 11.2$ & Transcriptional activation $\uparrow$ \\
\hline & $\begin{array}{l}\text { Pediatric } \\
\text { rhabdomyosarcoma }\end{array}$ & CpG methylation & Promoter & Transcriptional activation $\downarrow$ \\
\hline
\end{tabular}

AMK, acute megakaryoblastic leukaemia; B-ALL, B-cell acute lymphoblastic leukaemia; CHD, congenital heart disease; CML, chronic myeloid leukaemia; DCML, dendritic cell, monocyte, B-lymphocyte and natural killer lymphocyte deficiency; DEL, deletion; DLBCL, diffuse large B-cell lymphoma; DS, Down syndrome; GI, cancer gastrointestinal cance; FS, frameshift; HDR, hypoparathyreoidism, sensorineural deafness and renal disease; INS, insertion; MS, mut missense mutation; MonoMAC, syndrome associated with monocytopenia, B and NK, cell lymphopenia and mycobacterial, fungal and viral infections; NS, mut nonsense mutation; RCC, renal cell carcinoma; SNP, single nucleotide polymorphism; T-ALL, T-cell acute lymphoblastic leukaemia; TMD, transient myeoloproliferative disorder; UCC, urothelial cell carcinoma; XLT, X-linked thrombocytopenia; XLTT, X-linked thrombocytopenia with thalassemia.

(Ref. 46). Most mutations affect the C-terminal zinc finger or result in N-terminal frameshift mutations (Ref. 47).

Similar expression patterns of GATA1, GATA2 and GATA3 in human, murine and avian erythroid cells indicate a conserved role for these GATA transcription factors in vertebrate erythropoiesis (Ref. 48). Beyond its expression in erythroid lineages, GATA3 is also expressed in $\mathrm{T}$ lymphocytes (Ref. 49). During haematopoiesis vertebrate GATA3 is expressed in
HSCs and in developing $\mathrm{T}$ lymphocytes. Murine GATA3 ${ }^{-1-}$ embryos are predominantly affected during definitive haematopoiesis in the fetal liver. Although later than GATA2 $2^{-1-}$ mice, these embryos appear also anaemic and die in utero, probably owing to massive internal bleeding (Table 2) (Ref. 7). Frelin et al. demonstrated that GATA3 regulates the selfrenewal and differentiation of bone marrow long-term HSCs (Ref. 50). During embryogenesis, GATA3 deficiency leads to a marked reduction in the production 
of HSCs in the aorta-gonads-mesonephros region. It was shown that GATA3 regulates HSC emergence during embryogenenis via the production of catecholamines linking the haematopoietic system development to the development of the sympathetic nervous system (SNS) (Ref. 51).

In T cell development, GATA3 has a pivotal role from the generation of early $\mathrm{T}$ lineage progenitors to $\mathrm{CD}^{+}$specification [as reviewed in (Ref. 52)]. During antigen presentation by specialised antigen-presenting cells, the TCR is stimulated, thereby driving differentiation from peripheral naïve $\mathrm{CD}^{+} \mathrm{T}$ cells towards $\mathrm{T}$ helper cell type $1\left(\mathrm{~T}_{\mathrm{H}} 1\right)$ or $2\left(\mathrm{~T}_{\mathrm{H}} 2\right)$. GATA3 expression in differentiating $\mathrm{T}_{\mathrm{H}} 2$ cells is mediated by different pathways as clearly reviewed in Ho et al. (Ref. 53). GATA3 and STAT6 in $\mathrm{T}_{\mathrm{H}} 2$ lineage account for lineage specific expression of $\mathrm{T}$ cell lincRNAs. At the moment, the function of lincRNAs during $\mathrm{T}$ cell development and differentiation is under investigation (Ref. 54). An essential function for GATA3 beyond $\mathrm{T}_{\mathrm{H}} 2$ differentiation is also described demonstrating GATA 3 controls proliferation and maintenance of mature T cells (Ref. 55).

GATA3 dysregulation is described in leukaemia. Together with T-cell acute lymphocytic leukemia 1 (TAL1) and RUNX1, GATA3 forms an autoregulatory loop that positively regulates the $\mathrm{v}$-myb avian myeloblastosis viral oncogene (MYB) oncogene, which in turn controls the gene expression program in T-cell acute lymphoblastic leukaemia (T-ALL) (Ref. 56). Thereby, whole-genome sequencing of patients with early T-cell precursor ALL, an aggressive subtype of T-ALL, revealed GATA3 inactivating mutations (Supplemental Table 1) (Ref. 57).

In summary, GATA1/2/3 are essential regulators in the development of erythroid and megakaryocytic cell lineages and in the molecular pathogenesis of different haematopoietic diseases.

\section{Cardiovascular system}

The mesoderm gives rise to numerous organs, including the heart and genitourinary tract. GATA4/5/6 proteins are expressed in the mesodermal precursors that develop into the heart (Ref. 58).

GATA4 is one of the earliest transcription factors expressed in developing cardiac cells, already detectable in murine precardiac splanchnic mesoderm and associated endoderm (Ref. 8). GATA4 ${ }^{-1-}$ mice display severe defects in ventral foregut closure and heart morphogenesis, resulting in embryonic lethality at embryonic day 8 (Table 2). These deformities result from a general loss in ventral folding throughout the embryo and implicate GATA4 requirement for the migration or folding morphogenesis of the precardiogenic splanchic mesodermal cells (Ref. 8). Mice harbouring a knock-in mutation that abrogates the interaction with FOG-cofactors (GATA4 ${ }^{K i / K i}$ ) lack coronary vessels (Ref. 59). In addition, murine GATA4 regulates cardiac angiogenesis by inducing angiogenic factors such as VEGF, facilitating compensation following injury (Ref. 60). Yamak et al. have suggested that GATA4 and Cyclin D2 are part of a forward reinforcing loop in which Cyclin D2 feeds back to enhance cardiogenic activity of GATA4 through direct interaction. GATA4 mutations that abrogate Cyclin D2 interactions are associated with human CHD (Ref. 61).

A variety of GATA4 mutations have been detected in patients with various forms of CHD such as Tetralogy of Fallot, ventricular septal defect and atrial fibrillation as reviewed by McCulley et al and summarised in Table 3 and Supplemental Table 1 (Ref. 62).

Within the developing heart, GATA5 is expressed in the myocardium as well as in the endocardium and derived endocardial cushions in mouse embryos (Ref. 63). Depending on how GATA5 is inactivated in several mouse models, different cardiac phenotypes are described. Deletion of both GATA5 isoforms leads to hypoplastic hearts and partially penetrant bicuspid aortic valve formation (Ref. 64). When a GATA5 mutant allele was established that lacked the two zinc finger domains, cardiovascular defects were only detectable in a GATA4 $^{+/-}$background (Ref. 65). Although little is known about GATA5 in human heart conditions, three heterozygous GATA5 mutations have been associated with familial atrial fibrillation (Ref. 66) and four heterozygous GATA5 mutations with CHD (Ref. 67).

GATA6 is abundantly expressed in vascular smooth muscle cells during murine embryonic and postnatal development (Ref. 68). GATA6 ${ }^{-1-}$ mice die at the embryonic stage due to defects of the extra-embryonic endoderm (Table 2) (Ref. 10). Tissue-specific deletion of GATA6 in neural crest-derived smooth muscle cells results in an interrupted aortic arch and persistent truncus arteriosus (PTA). These results suggest that GATA6 is required for proper patterning of the aortic arch arteries. This phenotype is associated with severely attenuated expression of semaphorin $3 \mathrm{C}$, a signalling molecule critical for both neuronal and vascular patterning (Ref. 69). Other GATA6 target genes, e.g. Wnt2, in vascular smooth muscle cells and cardiac cells have been identified by microarray analysis after transient GATA6 over-expression. Interestingly, GATA6 is also a target of Wnt2 and together they form a feedforward transcriptional loop to regulate posterior cardiac development (Ref. 70).

A number of mutations have been described for GATA6 in the aetiology of CHD (Table 3; Supplemental Table 1). For example, two GATA6 mutations were found in patients with PTA disrupting the transcriptional activity of the GATA6 protein on downstream genes involved in the development of the cardiac outflow tract (Ref. 71).

Thus, the GATA4/5/6 transcription factors have closely related functions during cardiovascular development, and defects lead to CHD and other heart conditions.

\section{Gastrointestinal tract}

The endoderm gives rise to the respiratory and gastrointestinal tract as well as the associated organs such 
as pancreas and liver. Differentiation of embryonic stem cells towards the extra-embryonic endoderm can be induced by forced expression of either GATA4 or GATA6 (Ref. 72). Targeted mutagenesis of GATA4 in mouse embryonic stem cells results in disturbed differentiation of the visceral endoderm, suggesting that GATA4 has a role in yolk sac formation (Ref. 73).

Murine GATA4 is expressed in the proximal but not in the distal small intestine and has an important role in the maintenance of jejunal-ileal identities (Ref. 74). Furthermore, GATA4 is essential for jejunal functions such as fat and cholesterol absorption (Ref. 75). Beuling et al. found that reduction of GATA4 activity in the intestine induces bile acid absorption in the proximal ileum, which can restore bile acid homeostasis in mice with an ileocaecal resection (Ref. 76).

Whereas GATA4 expression is absent from the distal ileum, GATA6 is expressed throughout the entire small intestine. Conditional deletion of GATA6 in the ileum results in a decrease of crypt cell proliferation and numbers of enteroendocrine and Paneth cells, an increase in numbers of goblet-like cells in crypts and altered expression of genes specific to absorptive enterocytes. GATA4/ 6 factors are therefore required for proliferation, differentiation and gene expression in the small intestine (Ref. 77).

In humans, GATA4 and GATA5 are expressed in normal gastric and colon mucosa (Refs 78,79$)$. In gastric and colorectal cancer (CRC) these genes are frequently transcriptionally silenced by methylation (Refs 80, 78). In addition, we reported that GATA4 and GATA5 exhibit tumour suppressive properties in human CRC cells in vitro (Ref. 80). The potential biomarker capacities of GATA4 are discussed below.

\section{Liver and pancreas}

In the mouse, the ventral foregut endoderm differentiates to form the parenchymal components of the liver and ventral pancreas. Although GATA4 has an essential function in embryonic liver development, the protein seems to be dispensable in the adult liver function (Refs 81, 82). GATA6 $^{-1-}$ murine embryos have defects in endoderm differentiation, and show severely attenuated GATA4 expression levels and complete absence of hepatocyte nuclear factor 4 (HNF4) expression in the visceral endoderm, parietal endoderm and liver bud (Ref. 83). HNF4 is a key regulator for complete differentiation of visceral endoderm, hepatocyte differentiation and the epithelial transformation of the liver (Ref. 84). Tetraploid rescue experiments with GATA6 null mice show that GATA6 is a key regulator for liver bud growth and commitment of the endoderm to a hepatic cell fate (Ref. 83).

Development of the ventral pancreas was, in contrast to the dorsal pancreas, impaired in GATA4 ${ }^{-1-}$ murine embryos using tetraploid rescue experiments. GATA6 $^{-1-}$ embryos show a similar phenotype, although not as severe as that observed in GATA4 $^{-1-}$ embryos (Ref. 81). In humans, the role of GATA6 in pancreatic development became apparent in a group of patients with pancreatic agenesis, in which Allen et al. identified 15 de novo heterozygous inactivating mutations in GATA6 (Supplemental Table 1). In addition, these patients suffered from CHD, biliary tract abnormalities, gut developmental disorders, neurocognitive abnormalities and other endocrine abnormalities (Ref. 85). In contrast to these results, Martinelli et al. described that GATA6 is dispendable for pancreas development. However, GATA6 is essential for acinar differentiation and maintenance of adult exocrine homeostasis in mice (Ref. 86). An explanation for this contradiction might be the timepoint of GATA6 inactivation which is earlier in agenesis patients compared with the mouse model used by Martinelli et al. Together these data show the need for further research to unravel the role of GATA6 in pancreatic development.

In pancreatic cancer, GATA6 is often overexpressed, which correlates with GATA6 amplification (Table 3) (Ref. 87). Retained GATA6 expression has been shown in gastric, colorectal, esophageal, ovarian and pulmonary cancer cell lines (Refs 78, 88, 89, 90). Additionally, intestinal GATA6 expression is higher in proliferating progenitor cells compared with differentiated cells (Ref. 91). In primary gastric cancer, the pro-oncogenic effects of GATA6 are recently confirmed, in vitro and in vivo (Ref. 92).

\section{Urogenital tract and kidney}

GATA1 is abundantly expressed in the Sertoli cells of the testis during murine prepubertal testis development (Fig. 2). GATA1 expression decreases thereafter and is in the adult mouse testis only found in the Sertoli cells during different stages of the spermatogenesis (Ref. 93). Surprisingly, Sertoli-specific GATA1 knockout mice show no alterations in testis development, spermatogenesis, male fertility and expression of putative testis-specific GATA1 target genes (Ref. 94). Further research has to clarify whether there is a functional redundancy between GATA factors in the testis.

During urogenital development, GATA4 is expressed in somatic ovarian and testicular cell lineages, and is suggested to have an important regulatory role in gonadal gene expression (Fig. 2) (Ref. 95). Mouse embryos conditionally deficient in GATA4 show no formation of the genital ridge, the structure which differentiates into either testis or ovary (Ref. 96). GATA4 $4^{k i / k i}$ mice and $F O G 2^{-1-}$ mice display defects in the gonadogenesis in both sexes (Ref. 97). SRY (Y chromosome-linked testis-determining gene), MIS (Mullerian inhibiting substance) and SOX9 expression, which is critical for testis formation, are dependent on GATA $4 \times$ FOG 2 interaction (Ref. 98). Recently, a signalling cascade was suggested describing transduction of the p38 mitogen-activated protein kinase (MAPK) pathway by MAP3K4 and GADD45G which leads to GATA4 phosphorylation and thereby activation. Phosphorylated GATA4 then binds and activates the $S R Y$ promoter (Ref. 99). 
The GATA4 gene has also been implicated in a disorder of sex development (DSD). A GATA4 mutation, which abrogates the binding with FOG2, was discovered in a family with both CHD and 46,XY DSD (Table 3) (Ref. 100). The phenotype closely resembles that of the mouse GATA4 ${ }^{k i / k i}$ model (Ref. 97). The data described above indicate that GATA4, in combination with FOG2, is necessary for proper mammalian sex differentiation.

Murine GATA5 is expressed in the urogenital ridge during foetal development (Ref. 63). GATA5 ${ }^{-1-}$ female mice exhibit abnormalities of the genitourinary tract including malpositioning of the urogenital sinus, vagina and urethra, whereas males are unaffected (Table 2). These defects suggest that early morphogenic movements in the lower genitourinary tract are disrupted in the absence of GATA5. GATA5 and GATA6 are coexpressed in the developing urogenital ridge but do not seem to have entirely overlapping functions during development of the female genitourinary system (Ref. 9).

GATA6 is expressed during both testicular and ovarian fetal development (Fig. 2) (Ref. 63). In the developing gonads, GATA4 and GATA6 have overlapping, but distinct expression patterns, which suggest different roles for these transcription factors. In addition, it is also possible that these factors complement each other's functions because GATA4 and GATA6 are expressed in similar cell types in the testis and ovary (Refs 101, 102).

Loss of GATA6 expression has been found in ovarian cancer and has been associated with hypoacetylation of histones $\mathrm{H} 3$ and $\mathrm{H} 4$ and loss of H3K4me3 at the promoter region (Ref. 90). Downregulation of GATA6 expression results in nuclear deformation and aneuploidy of ovarian surface epithelial cells (Ref. 103). In contrast to other cancers, these data indicate a tumour suppressor role for GATA6 in ovarian cancer. Tumour suppressing activities are also suggested for GATA4 and GATA5 whereas introduction of these genes into ovarian tumour cell lines greatly inhibits cell growth and survival (Ref. 104).

During pronephros formation human GATA3 expression is already detected in the nephric duct (Fig. 2) (Ref. 105). Subsequently, ureter tips and the collecting duct system of the metanephros are formed, which both show GATA3 expression (Ref. 106). Inactivation of the murine GATA3 locus results in a morphologically abnormal nephric duct with an aberrant elongation path, loss of ureteric bud and a severe growth disturbance of de mesonephros due to the disturbance of a regulatory cascade consisting of GATA3 with $\beta$-catenin as upstream regulator and Ret as downstream target (Ref. 107).

In humans, GATA3 haploinsufficiency leads to the HDR syndrome, a rare and complex disease characterised by the combination of HDR, associated with GATA3 mutations (Table 3, Supplemental Table 1) (Ref. 108). The majority of these mutations leads to loss of DNA binding caused by a disrupted $\mathrm{ZnF} 2$, or altered FOG2 interaction and/or DNA binding affinity by a disrupted ZnF1 (Table 3). Most of the HDR probands without GATA3 mutations do not have renal abnormalities and no GATA3 mutations are found in patients with isolated hypoparathyreoidism (Ref. 109). This suggests that GATA3 mutations are highly penetrant and result in the HDR phenotype. In addition, GATA3 ${ }^{+/-}$mice show small size parathyroids resulting in failure to correct hypocalcaemia similar to HDR patients (Ref. 110). When GATA3 is specifically deleted in the developing inner ear, defective formation of the cochlear prosensory domain and loss of spiral ganglion neurons is shown (Ref. 111). However, the exact mechanisms leading to the HDR phenotype remain to be elucidated.

\section{Respiratory tract}

The mammalian lung develops from budding of the foregut endoderm, in which both GATA4 and GATA6 are expressed. In vitro analysis of lung development from GATA4 ${ }^{k i / k i}$ mice show abnormal lobar development, revealing GATA4 as a candidate for FOG2-mediated early pulmonary development (Ref. 112). GATA6-regulated Wnt signalling controls the balance between bronchioalveolar stem cell expansion and epithelial differentiation required for both lung development and regeneration after lung injury (Ref. 113).

However, data about defects in GATA factors in lung diseases are scarce. Recently, GATA2 requirement for oncogenic Kras-driven lung tumorigenenis was reported. Moreover, inhibition of GATA2 regulated pathways in mice with $K R A S$ mutant non-small cell lung cancer results in tumour regression (Ref. 114). Finally, a lung cancer susceptibility locus downstream of GATA3 was identified (Ref. 115).

\section{Mammary gland}

Using GATA3/LacZ knock-in mice, GATA3 expression is observed at the earliest stages of embryonic mammary development (Fig. 2). During puberty GATA3 is expressed in the terminal-end buds and within the adult mammary gland only in luminal epithelial cells. Targeted GATA3 deletion at different stages of the embryonic mammary development showed loss or absence of mammary primordia and nipples (Ref. 116). Postnatal GATA3 deletion resulted in loss of mammary gland development, and diminished expression of luminal differentiation markers, which indicates an important role of GATA3 in the luminal epithelium (Refs 116, 117). Loss of the oestrogen receptor $\alpha(E R \alpha)$ expression is observed in both GATA3 knock-out mice and FOG-2 knock-out mice (Ref. 117). Involvement of GATA3 and ERa in a positive cross-regulatory loop, which has been shown in breast cancer, may be an explanation for these phenomena (Ref. 118). Collectively, these data show that GATA3 is essential during embryonic development 
as well as the postnatal occurring morphogenesis (Ref. 116). Furthermore, GATA3 directs luminal differentiation of progenitor cells and is needed for active maintenance of the differentiated luminal phenotype (Ref. 117).

The crucial role of GATA3 in the mammary gland is further demonstrated by the observation of GATA3 mutations in $\sim 10 \%$ of human breast cancers. The spectrum of somatic mutations is diverse and cluster predominantly in the vicinity of the highly conserved C-terminal second zinc-finger (Table 3; Supplemental Table 1) (Ref. 119). Restoration of GATA3 in breast cancer cell lines leads to differentiation, suppressed tumour dissemination (Ref. 120), slower growth rates and induction of genes involved in luminal cell differentiation (Ref. 121). Thereby, GATA3 expression leads to reduced breast tumour outgrowth and inhibits pulmonary metastasis due to repression of metastasisassociated genes (Ref. 122). Recently it was described that GATA3 induces miR-29b expression, which in turn represses metastasis by changing tumour microenvironment (Ref. 123). Together these data indicate that GATA3 might function as a tumour suppressor gene. In vitro- and in vivo data support this potential tumour suppressor function because loss of GATA3 leads to tumor progression and tumour dissemination in a murine luminal breast cancer model (Ref. 120). Prognostic and predictive features of GATA3 as a biomarker in breast cancer are discussed below in the clinical applications section.

\section{Central Nervous System (CNS)}

GATA2 is expressed early during CNS development in murine embryos (Fig. 2) (Ref. 124). Despite early lethality of GATA2 $^{-1-}$ embryos (Table 2), several studies show that GATA2 is required for the development of sympathetic neurons (Ref. 125), serotonergic hindbrain neurons (Ref. 126), GABAergic midbrain neurons (Ref. 127), retinorecipient neurons (Ref. 128) and for the generation and cell fate determination of V2b spinal interneurons (Ref. 129). GATA2 ${ }^{-/-}$ embryos lack both GATA2 and GATA3 expression in the CNS, which indicates dependence of GATA3 expression on functional GATA2 during early differentiation of the neural tube (Ref. 130). The expression pattern of GATA3 during brain development is very similar to GATA2. GATA3 ${ }^{-1-}$ murine embryos also die early during embryonic development (Table 2) and have severe abnormalities of the brain and spinal cord (Ref. 7). Loss of GATA3 results in reduced Th (tyrosine hydroxylase) and Dbh (dopamine $\beta$-hydroxylase) transcripts, which consequently leads to noradrenaline deficiency in the SNS. Administration of catecholamine intermediates to pregnant female GATA $^{+1-}$ mice rescues GATA3 ${ }^{-1-}$ murine embryos, thereby partially unraveling the GATA3 loss-induced lethality (Ref. 131). A transcriptional network, which includes GATA3 (Ref. 132), is essential for cell survival and differentiation of sympathetic neurons during embryonic development as well as during adult life (Ref. 133).

GATA4 is expressed in the embryonic and adult $\mathrm{CNS}$ and acts as a negative regulator of astrocyte proliferation and growth (Fig. 2) (Ref. 134). In the adult mouse and human, GATA6 is expressed in neurons, astrocytes, choroids plexus epithelium and endothelial cells (Fig. 2) (Ref. 135).

Loss of expression of GATA4 and GATA6 occurs in glioblastoma multiforme (GBM). Both GATA4 / 6 gene promoters were found to be methylated and for GATA4 also somatic mutations were found (Refs 136, 137). Limited evidence indicates that GATA4 regulates apoptosis-related genes in cultured GBM cell lines (Ref. 136). GATA6 was identified in a mouse astrocytoma model as a novel tumour suppressor gene. Knockdown of GATA6 expression in RasV12 or $p 53^{-1-}$ astrocytes led to acceleration of tumourigenesis. Mutations of GATA6 occur during malignant progression of murine and human astrocytomas (Ref. 135).

\section{Regulation of GATA genes and proteins in disease}

Although mainly GATA gene mutations have been described above, chromosomal alterations as well as regulation of GATA genes and proteins on transcriptional and post-transcriptional levels can also contribute to disease development.

Recently it has been shown that combined tet methylcytosine dioxygenase 2 (TET2) and fms related tyrosine kinase 3 (FLT3) mutations regulate epigenetic silencing of GATA2 by promotor hypermethylation in human AML (Ref. 138). In clear cell renal cell carcinomas downregulation of GATA3 expression by promoter hypermethylation results in decreased expression of TbetaRIII, a protein with tumour suppressor features, during disease progression (Ref. 139). Presence of suppressive histone (H3K27) trimethylation of GATA3 together with absence of the GATA3 protein in anaplastic large cell lymphoma implicates epigenetical contribution in the pathogenesis of this disease (Ref. 140). Clues about the transcriptional regulation of the GATA4 and GATA6 genes come from a SUMO-specific protease 2 (SENP2) knockout model. These mice have reduced expression of GATA4 and GATA6 and defects in the embryonic heart. In SENP2 deficient embryos sumoylation of CBX4, accumulates and occupies the promoters of GATA4 and GATA6, thereby leading to transcriptional repression (Ref. 141).

GATA4 is located at chromosome $8 \mathrm{p}$, a chromosomal locus frequently deleted in multiple tumour types such as colorectal and oesophageal cancer (Refs 142, 143). Alternatively GATA4 can be downregulated via epigenetic silencing, such as hypoacetylation of histones $\mathrm{H} 3$ and $\mathrm{H} 4$ (Ref. 90) and promoter $\mathrm{CpG}$ island hypermethylation, which has been observed in colorectal, gastric, oesophageal, lung, ovarian and HPV-driven oropharyngeal cancer, in GBM and in diffuse large B-cell lymphoma (Refs 80, 78, 88, 89, 104, 136, 
144, 145). In contrast, GATA4 amplification is recently described in certain gastric cancer which indicates a more oncogenic function (Ref. 92). Further studies are needed to unravel the molecular mechanisms of GATA4 amplified in comparison with GATA4 methylated gastric cancers.

GATA5 is located at chromosome $20 \mathrm{q} 13$, a locus which is often amplified and methylated in multiple cancer types. No coding sequence mutations in GATA4 and GATA5 have been described so far in colorectal- and breast cancer (Refs 146, 147). However, promoter methylation of GATA5 might be established in order to downregulate increased gene expression imposed by amplification. Identified post-transcriptional modifications on GATA proteins include acetylation, phosphorylation and methylation (Fig. 1). Protein stability of GATA2 and GATA3 is regulated by phosphorylation and ubiquitilation. Phosphorylation of GATA3 by respectively Cyclin-dependent kinase 1 (CDK1) and CDK2 was required for F-box/ WD repeat-containing protein 7 (Fbw)-7 mediated ubiquitilation and degradation and contributed to precise differentiation of HSCs and T-cell lineages (Refs 148, 149). How GATA acetylation influences transcriptional processes has been investigated for GATA1. It turns out that bromodomain protein Brd3 binds to acetylated GATA1 to regulate the chromatin occupancy at erythroid target genes (Ref. 150). For GATA4 post-transciptional modifications have mainly been studied in the context of hypertrophy of the heart. Activation of GATA4 occurs in part through acetylation by the transcriptional coactivator p300. Takaya et al. identified 4 GATA4 lysine residues that, when mutated, lacked p300-induced acetylation, DNA binding and transcriptional activities (Fig. 1) (Ref. 151). Phosphorylation of $\mathrm{p} 300$ by Cdk9 increases the ability of p300 to induce acetylation and DNA binding of GATA4 (Ref. 152). Alternatively, phosphorylation of GATA4 on serine 105 is critical for a productive cardiac hypertrophic response to stress stimulation in adult mice (Ref. 153). Deacetylation of GATA4, and subsequent suppression of transcriptional activation, is mediated by histone deacetylase 2 (HDAC2) and the small homeodomain factor Hopx (Ref. 154). Recently it was reported that the GATA4 protein is methylated by Polycomb-repressive complex 2 member Ezh2. This reduced the interaction with and acetylation by p300, thereby reducing GATA4's transcriptional activity (Ref 155). Together, this emphasises how important post-transciptional modifications are for the regulation of GATA activity.

\section{Clinical applications of GATA transcription factor alterations}

The above mentioned alterations in GATA factors might be applicable as biomarkers for early detection, diagnosis and prediction of prognosis and response to therapy.
Early detection markers. Non-invasive early diagnosis of CRC reduces mortality of this disease (Ref. 156). We have shown that GATA4 promoter methylation is highly prevalent in $\mathrm{CRC}$, suggesting that methylation is an early event in colorectal carcinogenesis. GATA4 methylation, detected in faecal DNA has potential to be used as a biomarker for improving pre-selection tests for colonoscopy (Ref. 80), especially if the clinical and analytical sensitivity and specificity can be improved by adding additional biomarkers and by introducing sensitive analysis techniques such as for example methylation on beads technology (Ref. 157).

Diagnostic markers. The expression of several GATA factors can be helpful in establishing a correct diagnosis. In ovarian cancer loss of GATA4 precedes loss of GATA6 expression and can differentiate between histological subtypes. Loss of both GATA4 and GATA6 expression is found in serous, clear cell and endometrioid ovarian cancer, but their expression can be detected in mucinous carcinomas (Ref. 158).

Prognostic markers. As already described above, GATA1 mutations are found in nearly all AMKL patients with Down syndrome and are already detectable in the precursor lesion TMD. In addition, Down syndrome-neonates without GATA1 mutations do not develop AMKL (Refs 159, 160). Together, the presence of GATA1 mutations in Down syndrome-children might be a potential prognostic marker for identifying infants at higher risk of developing AMKL (Ref. 161). Besides having a clinical value in AMKL, prognostic properties of GATA transcription factors are also described in T-ALL. Inherited genetic GATA3 variants are identified in Philadelphia-like ALL (an ALL subtype with a poor prognosis) and are associated with early treatment response and a higher risk of relapse (Ref. 162).

GATA3 downregulation has been observed in ERnegative breast cancers and has been described as a strong prognostic indicator of breast cancer. Low GATA3 expression was strongly associated with aggressive disease and poor survival (Ref. 117). Vice versa, breast cancers expressing GATA3- and estrogen regulated genes exhibit a good prognosis and have better relapse-free and overall survival (Ref. 163). GATA3 has been considered to be a better prognostic marker for disease-free survival than commonly used variables such as ER status (Ref. 164) although conflicting data have been published. However, GATA3 expression is highly correlated with the luminal A subtype which has a relatively favourable outcome compared with luminal $\mathrm{B}$ and basal-like subtypes (Ref. 165). An explanation could be the downregulation of $p 18^{I N K 4 C}$ transcription by GATA3 resulting in expansion of luminal progenitor cells thereby favouring the development of luminal type breast cancer (Ref. 166).

Recent studies indicate that GATA2 may be a useful biomarker for predicting prognosis in AML. GATA2 
mutations are frequent in patients with a biallelic CEBPA mutation and are associated with a better survival (Ref. 167).

In oropharyngeal carcinomas, a methylation signature of 5 gene promoters, including GATA4, correlates with improved survival (Ref. 144). Eventually, loss of expression of GATA4 in GBM is associated with unfavourable patient survival (Ref. 136).

Recently it has been described that low GATA6 expression in lung adenocarcinomas is linked to increased incidence of metastasis and poor outcome (Ref. 168).

Predictive markers. Whole genome sequencing of samples from patients with ER-positive breast cancer, participating in aromatase inhibitor clinical trials identified 18 significantly mutated genes, including GATA3. Mutant GATA3 correlated with suppression of proliferation upon aromatase inhibitor treatment and might therefore be a positive predictive marker for aromatase inhibitor response (Ref. 169).

Re-expression of GATA4 in GBM cells conferred sensitivity to temozolomide, a DNA alkylating agent used in GBM therapy (Ref. 136).

Recently, GATA5 methylation was described as a potential predictive marker for patients with high-risk non-muscle-invasive bladder tumours. These patients had a better survival after treatment with Bacillus Calmette-Guérin (BCG) when GATA5 was methylated (Ref. 170).

Therapeutic interventions. For regenerative medicine the generation of functional differentiated cell types is of great therapeutic interest. Since heart disease occurs frequently and the heart has little regenerative capacity after damage, procedures are sought that can transdifferentiate fibroblast into cardiac myocytes. A cocktail of transcription factors, including GATA4 converts cardiac non-myocytes into cardiomyocyte-like cells in vivo, and alleviates cardiac injury (Refs 171, 172). Also in mouse liver engineering experiments GATA4 was one of the essential factors that contributed to the conversion of fibroblasts into functional hepatocytelike cells (Ref. 173). These induced cells were able to restore liver function in half of fumarylacetoacetatehydrolase-deficient mice. GATA4 is thus one of the pivotal genes that in combination with other transcription factors can be utilised to improve heart and liver function after damage. These promising results are the first steps for bringing regenerative medicine to the clinic. More knowledge of the different GATA protein functions and their downstream target genes is necessary before therapeutic strategies can be developed.

\section{Conclusions and future perspectives}

An increasing number of studies are being published, describing expression and function of GATA genes during development in different species.
Causal relationships between aberrations in GATA genes and several human diseases have become apparent. Numerous mutations in the GATA genes have been described above. Many disease-associated mutations are located in and around the Zinc finger regions. As those mutations are not specifically limited to the two Zinc fingers themselves, it is clear that the whole region is important for the proteins to be fully operational. Most likely mutations hinder the correct folding of the proteins and thereby obstruct GATA proteins from binding to their relevant binding partners. The application of next-generation sequencing technologies through whole-genome, whole-exome and whole-transcriptome approaches allows for substantial advances, which is expected to reveal more diseaseassociated alterations whithin GATA genes.

A better understanding of the regulation of GATA factors on transcriptional, translational and post-translational levels will give more leads to how GATAs can be used as biomarkers. Prospective clinical trials, based on these data, are necessary to determine the translational value of GATA genes as biomarkers.

\section{Supplementary material}

To view supplementary material for this article, please visit http://dx.doi.org/10.1017/erm.2016.2

\section{References}

1. Simon M.C. (1995) Gotta have GATA. Nature Genetics 11, 9-11

2. He C., Cheng H. and Zhou R. (2007) GATA family of transcription factors of vertebrates: phylogenetics and chromosomal synteny. Journal of Biosciences 32, 1273-1280

3. Lowry J.A. and Atchley W.R. (2000) Molecular evolution of the GATA family of transcription factors: conservation within the DNA-binding domain. Journal of Molecular Evolution 50, 103-115

4. Morrisey E.E. et al. (1997) GATA-4 activates transcription via two novel domains that are conserved within the GATA-4/5/6 subfamily. Journal of Biological Chemistry 272, 8515-8524

5. Fujiwara Y. et al. (1996) Arrested development of embryonic red cell precursors in mouse embryos lacking transcription factor GATA-1. Proceedings of the National Academy of Sciences of the United States of America 93, 12355-12358

6. Tsai F.Y. et al. (1994) An early haematopoietic defect in mice lacking the transcription factor GATA-2. Nature 371, 221-226

7. Pandolfi P.P. et al. (1995) Targeted disruption of the GATA3 gene causes severe abnormalities in the nervous system and in fetal liver haematopoiesis. Nature Genetics 11, 40-44

8. Kuo C.T. et al. (1997) GATA4 transcription factor is required for ventral morphogenesis and heart tube formation. Genes \& Development 11, 1048-1060

9. Molkentin J.D. et al. (2000) Abnormalities of the genitourinary tract in female mice lacking GATA5. Molecular and Cellular Biology 20, 5256-5260

10. Morrisey E.E. et al. (1998) GATA6 regulates HNF4 and is required for differentiation of visceral endoderm in the mouse embryo. Genes \& Development 12, 3579-3590

11. Martin D.I. et al. (1990) Expression of an erythroid transcription factor in megakaryocytic and mast cell lineages. Nature 344, 444-447

12. Simon M.C. et al. (1992) Rescue of erythroid development in gene targeted GATA-1- mouse embryonic stem cells. Nature Genetics 1, 92-98

13. Yu C. et al. (2002) Targeted deletion of a high-affinity GATAbinding site in the GATA-1 promoter leads to selective loss of the eosinophil lineage in vivo. Journal of Experimental Medicine 195, 1387-1395 
14. Shimizu R. et al. (2001) In vivo requirements for GATA-1 functional domains during primitive and definitive erythropoiesis. EMBO Journal 20, 5250-5260

15. Takai J. et al. (2013) The Gata1 5' region harbors distinct cisregulatory modules that direct gene activation in erythroid cells and gene inactivation in HSCs. Blood 122, 3450-3460

16. Weiss M.J., Keller G. and Orkin S.H. (1994) Novel insights into erythroid development revealed through in vitro differentiation of GATA-1 embryonic stem cells. Genes \& Development 8, 1184-1197

17. Grass J.A. et al. (2003) GATA-1-dependent transcriptional repression of GATA-2 via disruption of positive autoregulation and domain-wide chromatin remodeling. Proceedings of the National Academy of Sciences of the United States of America 100, 8811-8816

18. Fujiwara Y. et al. (2004) Functional overlap of GATA-1 and GATA-2 in primitive hematopoietic development. Blood 103, 583-585

19. Hollanda L.M. et al. (2006) An inherited mutation leading to production of only the short isoform of GATA-1 is associated with impaired erythropoiesis. Nature Genetics 38, 807-812

20. Ludwig L.S. et al. (2014) Altered translation of GATA1 in Diamond-Blackfan anemia. Nature Medicine 20, 748-753

21. Shivdasani R.A. et al. (1997) A lineage-selective knockout establishes the critical role of transcription factor GATA-1 in megakaryocyte growth and platelet development. EMBO Journal 16, 3965-3973

22. Huang Z. et al. (2007) STAT1 promotes megakaryopoiesis downstream of GATA-1 in mice. Journal of Clinical Investigation 117, 3890-3899

23. Muntean A.G. and Crispino J.D. (2005) Differential requirements for the activation domain and FOG-interaction surface of GATA-1 in megakaryocyte gene expression and development. Blood 106, 1223-1231

24. Pimkin M. et al. (2014) Divergent functions of hematopoietic transcription factors in lineage priming and differentiation during erythro-megakaryopoiesis. Genome Research 24, 1932-1944

25. Wechsler J. et al. (2002) Acquired mutations in GATA1 in the megakaryoblastic leukemia of Down syndrome. Nature Genetics 32, 148-152

26. Calligaris R. et al. (1995) Alternative translation initiation site usage results in two functionally distinct forms of the GATA-1 transcription factor. Proceedings of the National Academy of Sciences of the United States of America 92, 11598-11602

27. Li Z. et al. (2005) Developmental stage-selective effect of somatically mutated leukemogenic transcription factor GATA1. Nature Genetics 37, 613-619

28. Groet J. et al. (2003) Acquired mutations in GATA1 in neonates with Down's syndrome with transient myeloid disorder. Lancet 361, 1617-1620

29. Hitzler J.K. et al. (2003) GATA1 mutations in transient leukemia and acute megakaryoblastic leukemia of Down syndrome. Blood 101, 4301-4304

30. Yoshida K. et al. (2013) The landscape of somatic mutations in Down syndrome-related myeloid disorders. Nature Genetics 45, 1293-1299

31. Nikolaev S.I. et al. (2013) Exome sequencing identifies putative drivers of progression of transient myeloproliferative disorder to AMKL in infants with Down syndrome. Blood 122, 554-561

32. Cabelof D.C. et al. (2009) Mutational spectrum at GATA1 provides insights into mutagenesis and leukemogenesis in Down syndrome. Blood 114, 2753-2763

33. Stankiewicz M.J. and Crispino J.D. (2013) AKT collaborates with ERG and GATA1s to dysregulate megakaryopoiesis and promote AMKL. Leukemia 27, 1339-1347

34. Roy A. et al. (2012) Perturbation of fetal liver hematopoietic stem and progenitor cell development by trisomy 21 . Proceedings of the National Academy of Sciences of the United States of America 109, 17579-17584

35. Chou S.T. et al. (2012) Trisomy 21-associated defects in human primitive hematopoiesis revealed through induced pluripotent stem cells. Proceedings of the National Academy of Sciences of the United States of America 109, 17573-17578

36. Maclean G.A. et al. (2012) Altered hematopoiesis in trisomy 21 as revealed through in vitro differentiation of isogenic human pluripotent cells. Proceedings of the National
Academy of Sciences of the United States of America 109, $17567-17572$

37. Satge D. (2014) Are GATA1 mutations occurring at random in Down syndrome transient leukemia? Medical Hypotheses $\mathbf{8 3}$, 154-159

38. Woo A.J. et al. (2013) Developmental differences in IFN signaling affect GATA1s-induced megakaryocyte hyperproliferation. Journal of Clinical Investigation 123, 13

39. Nichols K.E. et al. (2000) Familial dyserythropoietic anaemia and thrombocytopenia due to an inherited mutation in GATA1. Nature Genetics 24, 266-270

40. Freson K. et al. (2001) Platelet characteristics in patients with X-linked macrothrombocytopenia because of a novel GATA1 mutation. Blood 98, 85-92

41. Yu C. et al. (2002) X-linked thrombocytopenia with thalassemia from a mutation in the amino finger of GATA-1 affecting DNA binding rather than FOG-1 interaction. Blood 100, 2040-2045

42. Rodrigues N.P. et al. (2008) GATA-2 regulates granulocytemacrophage progenitor cell function. Blood 112, 4862-4873

43. Ling K.W. et al. (2004) GATA-2 plays two functionally distinct roles during the ontogeny of hematopoietic stem cells. Journal of Experimental Medicine 200, 871-882

44. Bresnick E.H. et al. (2012) Master regulatory GATA transcription factors: mechanistic principles and emerging links to hematologic malignancies. Nucleic Acids Research 40, 5819-5831

45. Zhang S.J. et al. (2008) Gain-of-function mutation of GATA-2 in acute myeloid transformation of chronic myeloid leukemia. Proceedings of the National Academy of Sciences of the United States of America 105, 2076-2081

46. Hahn C.N. et al. (2011) Heritable GATA2 mutations associated with familial myelodysplastic syndrome and acute myeloid leukemia. Nature Genetics 43, 1012-1017

47. Hyde R.K. and Liu P.P. (2011) GATA2 mutations lead to MDS and AML. Nature Genetics 43, 926-927

48. Leonard M.W., Lim K.C. and Engel J.D. (1993) Expression of the chicken GATA factor family during early erythroid development and differentiation. Development 119, 519-531

49. Ho I.C. et al. (1991) Human GATA-3: a lineage-restricted transcription factor that regulates the expression of the $\mathrm{T}$ cell receptor alpha gene. EMBO Journal 10, 1187-1192

50. Frelin C. et al. (2013) GATA-3 regulates the self-renewal of long-term hematopoietic stem cells. Nature Immunology 14, 1037-1044

51. Fitch S.R. et al. (2012) Signaling from the sympathetic nervous system regulates hematopoietic stem cell emergence during embryogenesis. Cell Stem Cell 11, 554-566

52. Hosoya T., Maillard I. and Engel J.D. (2010) From the cradle to the grave: activities of GATA-3 throughout T-cell development and differentiation. Immunological Reviews 238, 110-125

53. Ho I.C., Tai T.S. and Pai S.Y. (2009) GATA3 and the T-cell lineage: essential functions before and after T-helper-2-cell differentiation. Nature Reviews Immunology 9, 125-135

54. Hu G. et al. (2013) Expression and regulation of intergenic long noncoding RNAs during T cell development and differentiation. Nature Immunology 14, 1190-1198

55. Wang Y. et al. (2013) GATA-3 controls the maintenance and proliferation of T cells downstream of TCR and cytokine signaling. Nature Immunology 14, 714-722

56. Sanda T. et al. (2012) Core transcriptional regulatory circuit controlled by the TAL1 complex in human $\mathrm{T}$ cell acute lymphoblastic leukemia. Cancer Cell 22, 209-221

57. Zhang J. et al. (2012) The genetic basis of early T-cell precursor acute lymphoblastic leukaemia. Nature 481, 157-163

58. Brewer A. and Pizzey J. (2006) GATA factors in vertebrate heart development and disease. Expert Reviews in Molecular Medicine 8, 1-20

59. Crispino J.D. et al. (2001) Proper coronary vascular development and heart morphogenesis depend on interaction of GATA-4 with FOG cofactors. Genes \& Development 15, 839-844

60. Heineke J. et al. (2007) Cardiomyocyte GATA4 functions as a stress-responsive regulator of angiogenesis in the murine heart. Journal of Clinical Investigation 117, 3198-3210

61. Yamak A. et al. (2014) Cyclin D2 is a GATA4 cofactor in cardiogenesis. Proceedings of the National Academy of Sciences of the United States of America 111, 1415-1420 
62. McCulley D.J. and Black B.L. (2012) Transcription factor pathways and congenital heart disease. Current Topics in Developmental Biology 100, 253-277

63. Morrisey E.E. et al. (1997) GATA-5: a transcriptional activator expressed in a novel temporally and spatially-restricted pattern during embryonic development. Annual Review of Cell and Developmental Biology 183, 21-36

64. Laforest B., Andelfinger G. and Nemer M. (2011) Loss of Gata5 in mice leads to bicuspid aortic valve. Journal of Clinical Investigation 121, 2876-2887

65. Singh M.K. et al. (2010) Gata4 and Gata5 cooperatively regulate cardiac myocyte proliferation in mice. Journal of Biological Chemistry 285, 1765-1772

66. Yang Y.Q. et al. (2012) Mutational spectrum of the GATA5 gene associated with familial atrial fibrillation. International Journal of Cardiology 157, 305-307

67. Jiang J.Q. et al. (2013) Prevalence and spectrum of GATA5 mutations associated with congenital heart disease. International Journal of Cardiology 165, 570-573

68. Morrisey E.E. et al. (1996) GATA-6: a zinc finger transcription factor that is expressed in multiple cell lineages derived from lateral mesoderm. Developmental bBiology 177, 309-322

69. Lepore J.J. et al. (2006) GATA-6 regulates semaphorin 3C and is required in cardiac neural crest for cardiovascular morphogenesis. Journal of Clinical Investigation 116, 929-939

70. Tian Y. et al. (2010) Characterization and in vivo pharmacological rescue of a Wnt2-Gata6 pathway required for cardiac inflow tract development. Developmental Cell 18, 275-287

71. Kodo K. et al. (2009) GATA6 mutations cause human cardiac outflow tract defects by disrupting semaphorin-plexin signaling. Proceedings of the National Academy of Sciences of the United States of America 106, 13933-13938

72. Fujikura J. et al. (2002) Differentiation of embryonic stem cells is induced by GATA factors. Genes \& Development 16, 784-789

73. Soudais C. et al. (1995) Targeted mutagenesis of the transcription factor GATA-4 gene in mouse embryonic stem cells disrupts visceral endoderm differentiation in vitro. Development 121, 3877-3888

74. Boudreau F. et al. (2002) Hepatocyte nuclear factor-1 alpha, GATA-4, and caudal related homeodomain protein $\mathrm{Cdx} 2$ interact functionally to modulate intestinal gene transcription. Implication for the developmental regulation of the sucraseisomaltase gene. Journal of Biological Chemistry 277, 31909-31917

75. Battle M.A. et al. (2008) GATA4 is essential for jejunal function in mice. Gastroenterology 135, 1676-1686 e1

76. Beuling E. et al. (2010) Conditional Gata4 deletion in mice induces bile acid absorption in the proximal small intestine. Gut 59, 888-895

77. Beuling E. et al. (2011) GATA factors regulate proliferation, differentiation, and gene expression in small intestine of mature mice. Gastroenterology 140, 1219-1229 e1-2

78. Akiyama Y. et al. (2003) GATA-4 and GATA-5 transcription factor genes and potential downstream antitumor target genes are epigenetically silenced in colorectal and gastric cancer. Molecular and Cellular Biology 23, 8429-8439

79. Wen X.Z. et al. (2010) Methylation of GATA-4 and GATA-5 and development of sporadic gastric carcinomas. World Journal of Gastroenterology 16, 1201-1208

80. Hellebrekers D.M. et al. (2009) GATA4 and GATA5 are potential tumor suppressors and biomarkers in colorectal cancer. Clinical Cancer Research: An Official Journal of the American Association for Cancer Research 15, 3990-3997

81. Watt A.J. et al. (2007) Development of the mammalian liver and ventral pancreas is dependent on GATA4. BMC Developmental Biology 7, 37

82. Zheng R. et al. (2013) Function of GATA factors in the adult mouse liver. PloS ONE 8, e83723

83. Zhao R. et al. (2005) GATA6 is essential for embryonic development of the liver but dispensable for early heart formation. Molecular and Cellular Biology 25, 2622-2631

84. Parviz F. et al. (2003) Hepatocyte nuclear factor 4alpha controls the development of a hepatic epithelium and liver morphogenesis. Nature Genetics 34, 292-296

85. Lango Allen $H$. et al. (2012) GATA6 haploinsufficiency causes pancreatic agenesis in humans. Nature Genetics 44, 20-22
86. Martinelli P. et al. (2013) Gata6 is required for complete acinar differentiation and maintenance of the exocrine pancreas in adult mice. Gut 62, 1481-1488

87. Kwei K.A. et al. (2008) Genomic profiling identifies GATA6 as a candidate oncogene amplified in pancreatobiliary cancer. PLoS Genetics 4, e1000081

88. Guo M. et al. (2004) Hypermethylation of the GATA genes in lung cancer. Clinical Cancer Research: An Official Journal of the American Association for Cancer Research 10, 7917-7924

89. Guo M. et al. (2006) Hypermethylation of the GATA gene family in esophageal cancer. International Journal of Cancer. Journal International du Cancer 119, 2078-2083

90. Caslini C. et al. (2006) Histone modifications silence the GATA transcription factor genes in ovarian cancer. Oncogene 25, 5446-5461

91. Gao X. et al. (1998) Distinct functions are implicated for the GATA-4, -5 , and -6 transcription factors in the regulation of intestine epithelial cell differentiation. Molecular and Cellular Biology 18, 2901-2911

92. Chia N.Y. et al. (2014) Regulatory crosstalk between lineagesurvival oncogenes KLF5, GATA4 and GATA6 cooperatively promotes gastric cancer development. Gut 64, 707-719

93. Ito E. et al. (1993) Erythroid transcription factor GATA-1 is abundantly transcribed in mouse testis. Nature 362, 466-468

94. Lindeboom F. et al. (2003) A tissue-specific knockout reveals that Gatal is not essential for Sertoli cell function in the mouse. Nucleic Acids Research 31, 5405-5412

95. Viger R.S. et al. (1998) Transcription factor GATA-4 is expressed in a sexually dimorphic pattern during mouse gonadal development and is a potent activator of the Mullerian inhibiting substance promoter. Development $\mathbf{1 2 5}$, 2665-2675

96. Hu Y.C., Okumura L.M. and Page D.C. (2013) Gata4 is required for formation of the genital ridge in mice. PLoS Genetics 9, e1003629

97. Tevosian S.G. et al. (2002) Gonadal differentiation, sex determination and normal Sry expression in mice require direct interaction between transcription partners GATA4 and FOG2. Development 129, 4627-4634

98. Bouma G.J. et al. (2007) Correct dosage of Fog2 and Gata4 transcription factors is critical for fetal testis development in mice. Proceedings of the National Academy of Sciences of the United States of America 104, 14994-14999

99. Gierl M.S. et al. (2012) GADD45 G functions in male sex determination by promoting $\mathrm{p} 38$ signaling and Sry expression. Developmental Cell 23, 1032-1042

100. Lourenco D. et al. (2011) Loss-of-function mutation in GATA4 causes anomalies of human testicular development. Proceedings of the National Academy of Sciences of the United States of America 108, 1597-1602

101. Ketola I. et al. (1999) Expression and regulation of transcription factors GATA-4 and GATA-6 in developing mouse testis. Endocrinology 140, 1470-1480

102. Heikinheimo M. et al. (1997) Expression and hormonal regulation of transcription factors GATA-4 and GATA-6 in the mouse ovary. Endocrinology 138, 3505-3514

103. Capo-chichi C.D. et al. (2009) Loss of GATA6 leads to nuclear deformation and aneuploidy in ovarian cancer. Molecular and Cellular Biology 29, 4766-4777

104. Wakana K. et al. (2006) Involvement of GATA-4/-5 transcription factors in ovarian carcinogenesis. Cancer Letters 241, 281-288

105. George K.M. et al. (1994) Embryonic expression and cloning of the murine GATA-3 gene. Development 120, 2673-2686

106. Grote D. et al. (2006) Pax 2/8-regulated Gata 3 expression is necessary for morphogenesis and guidance of the nephric duct in the developing kidney. Development 133, 53-61

107. Chia I. et al. (2011) Nephric duct insertion is a crucial step in urinary tract maturation that is regulated by a Gata3-Raldh2Ret molecular network in mice. Development 138, 2089-2097

108. Van Esch H. et al. (2000) GATA3 haplo-insufficiency causes human HDR syndrome. Nature 406, 419-422

109. Ali A. et al. (2007) Functional characterization of GATA3 mutations causing the hypoparathyroidism-deafness-renal (HDR) dysplasia syndrome: insight into mechanisms of DNA binding by the GATA3 transcription factor. Human Molecular Genetics 16, 265-275 
110. Grigorieva I.V. et al. (2010) Gata3-deficient mice develop parathyroid abnormalities due to dysregulation of the parathyroid-specific transcription factor Gcm2. Journal of Clinical Investigation 120, 2144-2155

111. Luo X.J. et al. (2013) GATA3 controls the specification of prosensory domain and neuronal survival in the mouse cochlea. Human Molecular Genetics 22, 3609-3623

112. Ackerman K.G. et al. (2007) Gata4 is necessary for normal pulmonary lobar development. American Journal of Respiratory Cell and Molecular Biology 36, 391-397

113. Zhang Y. et al. (2008) A Gata6-Wnt pathway required for epithelial stem cell development and airway regeneration. Nature Genetics 40, 862-870

114. Kumar M.S. et al. (2012) The GATA2 transcriptional network is requisite for RAS oncogene-driven non-small cell lung cancer. Cell 149, 642-655

115. Dong J. et al. (2012) Association analyses identify multiple new lung cancer susceptibility loci and their interactions with smoking in the Chinese population. Nature Genetics 44, 895-899

116. Asselin-Labat M.L. et al. (2007) Gata-3 is an essential regulator of mammary-gland morphogenesis and luminal-cell differentiation. Nature Cell Biology 9, 201-209

117. Kouros-Mehr H. et al. (2006) GATA-3 maintains the differentiation of the luminal cell fate in the mammary gland. Cell 127, 1041-1055

118. Eeckhoute J. et al. (2007) Positive cross-regulatory loop ties GATA-3 to estrogen receptor alpha expression in breast cancer. Cancer Research 67, 6477-6483

119. Koboldt D.C. et al. (2012) Comprehensive molecular portraits of human breast tumours. Nature 490, 61-70

120. Kouros-Mehr H. et al. (2008) GATA-3 links tumor differentiation and dissemination in a luminal breast cancer model. Cancer Cell 13, 141-152

121. Usary J. et al. (2004) Mutation of GATA3 in human breast tumors. Oncogene 23, 7669-7678

122. Dydensborg A.B. et al. (2009) GATA3 inhibits breast cancer growth and pulmonary breast cancer metastasis. Oncogene 28, 2634-2642

123. Chou J. et al. (2013) GATA3 suppresses metastasis and modulates the tumour microenvironment by regulating microRNA$29 \mathrm{~b}$ expression. Nature Cell Biology 15, 201-213

124. Zhou W. et al. (2002) Counting alleles to predict recurrence of early-stage colorectal cancers. Lancet 359, 219-225

125. Tsarovina K. et al. (2004) Essential role of Gata transcription factors in sympathetic neuron development. Development 131, 4775-4786

126. Craven S.E. et al. (2004) Gata2 specifies serotonergic neurons downstream of sonic hedgehog. Development 131, 1165-1173

127. Kala K. et al. (2009) Gata2 is a tissue-specific postmitotic selector gene for midbrain GABAergic neurons. Development 136, 253-262

128. Willett R.T. and Greene L.A. (2011) Gata2 is required for migration and differentiation of retinorecipient neurons in the superior colliculus. Journal of Neuroscience: The Official Journal of the Society for Neuroscience 31, 44444455

129. Zhou Y., Yamamoto M. and Engel J.D. (2000) GATA2 is required for the generation of V2 interneurons. Development 127, 3829-3838

130. Karunaratne A. et al. (2002) GATA proteins identify a novel ventral interneuron subclass in the developing chick spinal cord. Developmental bBiology 249, 30-43

131. Lim K.C. et al. (2000) Gata3 loss leads to embryonic lethality due to noradrenaline deficiency of the sympathetic nervous system. Nature Genetics 25, 209-212

132. Goridis C. and Rohrer H. (2002) Specification of catecholaminergic and serotonergic neurons. Nature Reviews. Neuroscience 3, 531-541

133. Tsarovina K. et al. (2010) The Gata3 transcription factor is required for the survival of embryonic and adult sympathetic neurons. Journal of Neuroscience: The Official Journal of the Society for Neuroscience 30, 10833-10843

134. Agnihotri S. et al. (2009) GATA4 is a regulator of astrocyte cell proliferation and apoptosis in the human and murine central nervous system. Oncogene 28, 3033-3046

135. Kamnasaran D. et al. (2007) GATA6 is an astrocytoma tumor suppressor gene identified by gene trapping of mouse glioma model. Proceedings of the National Academy of Sciences of the United States of America 104, 8053-8058

136. Agnihotri S. et al. (2011) A GATA4-regulated tumor suppressor network represses formation of malignant human astrocytomas. Journal of Experimental Medicine 208, 689-702

137. Martinez R. et al. (2009) A microarray-based DNA methylation study of glioblastoma multiforme. Epigenetics: Official Journal of the DNA Methylation Society 4, 255-264

138. Shih A.H. et al. (2015) Mutational cooperativity linked to combinatorial epigenetic gain of function in acute myeloid leukemia. Cancer Cell 27, 502-515

139. Cooper S.J. et al. (2010) Loss of type III transforming growth factor-beta receptor expression is due to methylation silencing of the transcription factor GATA3 in renal cell carcinoma. Oncogene 29, 2905-2915

140. Joosten M. et al. (2013) Histone acetylation and DNA demethylation of $\mathrm{T}$ cells result in an anaplastic large cell lymphoma-like phenotype. Haematologica 98, 247-254

141. Kang X. et al. (2010) SUMO-specific protease 2 is essential for suppression of polycomb group protein-mediated gene silencing during embryonic development. Molecular Cell 38, 191-201

142. Derks S. et al. (2006) Promoter methylation precedes chromosomal alterations in colorectal cancer development. Cellular Oncology 28, 247-257

143. Lin L. et al. (2000) A minimal critical region of the 8p22-23 amplicon in esophageal adenocarcinomas defined using sequence tagged site-amplification mapping and quantitative polymerase chain reaction includes the GATA-4 gene. Cancer Research 60, 1341-1347

144. Kostareli E. et al. (2013) HPV-related methylation signature predicts survival in oropharyngeal squamous cell carcinomas. Journal of Clinical Investigation 123, 2488-2501

145. Pike B.L. et al. (2008) DNA methylation profiles in diffuse large B-cell lymphoma and their relationship to gene expression status. Leukemia 22, 1035-1043

146. Sjoblom T. et al. (2006) The consensus coding sequences of human breast and colorectal cancers. Science 314, 268-274

147. Wood L.D. et al. (2007) The genomic landscapes of human breast and colorectal cancers. Science 318, 1108-1113

148. Kitagawa K. et al. (2014) Fbw7 targets GATA3 through cyclin-dependent kinase 2-dependent proteolysis and contributes to regulation of T-cell development. Molecular and Cellular Biology 34, 2732-2744

149. Nakajima T. et al. (2015) Regulation of GATA-binding protein 2 levels via ubiquitin-dependent degradation by Fbw7: involvement of cyclin B-cyclin-dependent kinase 1mediated phosphorylation of THR176 in GATA-binding protein 2. Journal of Biological Chemistry 290, 10368-10381

150. Lamonica J.M. et al. (2011) Bromodomain protein Brd3 associates with acetylated GATA1 to promote its chromatin occupancy at erythroid target genes. Proceedings of the National Academy of Sciences of the United States of America 108, E159-E168

151. Takaya T. et al. (2008) Identification of p300-targeted acetylated residues in GATA4 during hypertrophic responses in cardiac myocytes. Journal of Biological Chemistry 283, 9828-9835

152. Sunagawa Y. et al. (2010) Cyclin-dependent kinase-9 is a component of the p300/GATA4 complex required for phenylephrine-induced hypertrophy in cardiomyocytes. Journal of Biological Chemistry 285, 9556-9568

153. van Berlo J.H. et al. (2011) Serine 105 phosphorylation of transcription factor GATA4 is necessary for stress-induced cardiac hypertrophy in vivo. Proceedings of the National Academy of Sciences of the United States of America 108, 12331-12336

154. Trivedi C.M. et al. (2010) Hopx and Hdac2 interact to modulate Gata4 acetylation and embryonic cardiac myocyte proliferation. Developmental Cell 19, 450-459

155. He A. et al. (2012) PRC2 directly methylates GATA4 and represses its transcriptional activity. Genes \& Development 26, 37-42

156. Hewitson P. et al. (2008) Cochrane systematic review of colorectal cancer screening using the fecal occult blood test (hemoccult): an update. American Journal of Gastroenterology 103, 1541-1549 
157. Guzzetta A.A. et al. (2014) The promise of methylation on beads for cancer detection and treatment. Expert Review of Molecular Diagnostics 14, 845-852

158. Cai K.Q. et al. (2009) Loss of GATA4 and GATA6 expression specifies ovarian cancer histological subtypes and precedes neoplastic transformation of ovarian surface epithelia. PloS ONE 4, e6454

159. Pine S.R. et al. (2007) Incidence and clinical implications of GATA1 mutations in newborns with Down syndrome. Blood 110, 2128-2131

160. Roberts I. et al. (2013) GATA1-mutant clones are frequent and often unsuspected in babies with Down syndrome: identification of a population at risk of leukemia. Blood 122, 3908-3917

161. Roy A. et al. (2009) Acute megakaryoblastic leukaemia (AMKL) and transient myeloproliferative disorder (TMD) in Down syndrome: a multi-step model of myeloid leukaemogenesis. British Journal of Haematology 147, 3-12

162. Perez-Andreu V. et al. (2013) Inherited GATA3 variants are associated with Ph-like childhood acute lymphoblastic leukemia and risk of relapse. Nature Genetics 45, 1494-1498

163. Oh D.S. et al. (2006) Estrogen-regulated genes predict survival in hormone receptor-positive breast cancers. Journal of Clinical Oncology 24, 1656-1664

164. Mehra R. et al. (2005) Identification of GATA3 as a breast cancer prognostic marker by global gene expression metaanalysis. Cancer Research 65, 11259-11264

165. Albergaria A. et al. (2009) Expression of FOXA1 and GATA3 in breast cancer: the prognostic significance in hormone receptor-negative tumours. Breast Cancer Research 11, R40

166. Pei X.H. et al. (2009) CDK inhibitor p18(INK4c) is a downstream target of GATA3 and restrains mammary luminal progenitor cell proliferation and tumorigenesis. Cancer Cell 15, 389-401

167. Fasan A. et al. (2013) GATA2 mutations are frequent in intermediate-risk karyotype AML with biallelic CEBPA mutations and are associated with favorable prognosis. Leukemia 27, 482-485

168. Cheung W.K. et al. (2013) Control of alveolar differentiation by the lineage transcription factors GATA6 and HOPX inhibits lung adenocarcinoma metastasis. Cancer Cell 23, 725-738
169. Ellis M.J. et al. (2012) Whole-genome analysis informs breast cancer response to aromatase inhibition. Nature 486, 353-360

170. Agundez M. et al. (2011) Evaluation of the methylation status of tumour suppressor genes for predicting bacillus CalmetteGuerin response in patients with T1G3 high-risk bladder tumours. European Urology 60, 131-140

171. Song K. et al. (2012) Heart repair by reprogramming nonmyocytes with cardiac transcription factors. Nature $\mathbf{4 8 5}$, 599-604

172. Qian L. et al. (2012) In vivo reprogramming of murine cardiac fibroblasts into induced cardiomyocytes. Nature 485, 593-598

173. Huang P. et al. (2011) Induction of functional hepatocyte-like cells from mouse fibroblasts by defined factors. Nature $\mathbf{4 7 5}$, 386-389

Further reading, resources and contacts

Disease pages in OMIM

GATA1: http://www.omim.org/entry/305371?search=GATA1\& highlight $=$ gata 1

GATA2: http://www.omim.org/entry/137295?search=GATA2\& highlight $=$ gata2

GATA3: http://www.omim.org/entry/131320?search=GATA3\& highlight=gata3

GATA4: http://www.omim.org/entry /600576? search=GATA4\& highlight=gata4

GATA5: http://www.omim.org/entry/611496?search=GATA5\& highlight=gata5

GATA6: http://www.omim.org/entry/601656?search=GATA6\& highlight $=$ gata 6

*Corresponding author:

Prof Dr Manon van Engeland,

Department of Pathology,

GROW - School for Oncology and Developmental Biology,

Maastricht University Medical Center,

P.O. Box 616,

6200 MD Maastricht, The Netherlands.

Tel: +31-43-3885498;

Fax: +31-43-3876613;

E-mail: manon.van.engeland@mumc.nl 